\title{
Fotossíntese De BIótipos de AZevém SOB Condição de COMPETIÇÃo
}

\author{
Photosynthesis of Ryegrass Biotypes Under Different Competition Levels
}

\author{
CONCENÇO, G. ${ }^{2}$, FERREIRA, E.A. ${ }^{3}$, SILVA, A.A. ${ }^{4}$, FERREIRA, F.A. ${ }^{4}$, GALON, L. ${ }^{2}$, REIS, M.R. ${ }^{2}$, \\ d'ANTONINO, L. ${ }^{2}$, VARGAS, L. ${ }^{5}$ e SILVA, L.V.B.D. ${ }^{6}$
}

\begin{abstract}
RESUMO - As características associadas à atividade fotossintética de biótipos de azevém, resistente e suscetivel ao herbicida glyphosate, foram avaliadas sob diferentes niveis de competição entre biótipos. O experimento foi realizado em esquema fatorial $2 \times 5$, com dois biótipos de azevém, resistente e suscetivel ao glyphosate, cultivados em planta única no centro da parcela, competindo com zero, um, dois, três ou quatro plantas do biótipo oposto. Cinqüenta dias após a emergência, foram determinadas a taxa de fluxo de gases pelos estômatos ( $\left.\mathrm{U}-\mu \mathrm{mol} \mathrm{s} \mathrm{s}^{-1}\right)$, a concentração de $\mathrm{CO}_{2}$ subestomática $\left(\mathrm{Ci}-\mu \mathrm{mol} \mathrm{mol}{ }^{-1}\right)$ e a taxa fotossintética (A - $\left.\mu \mathrm{mol} \mathrm{m} \mathrm{m}^{-2} \mathrm{~s}^{-1}\right)$, sendo calculado ainda o $\mathrm{CO}_{2}$ consumido $\left(\Delta \mathrm{C}-\mu \mathrm{mol} \mathrm{mol}^{-1}\right)$ a partir dos valores de $\mathrm{CO}_{2}$ de referência e $\mathrm{CO}_{2}$ na câmara de avaliação. Os dados foram coletados utilizando-se analisador de gases no infravermelho (IRGA), marca ADC, modelo LCA 4. Foi elaborada matriz de correlação entre as variáveis. Os biótipos de azevém resistente e suscetivel ao glyphosate não diferiram quanto à atividade fotossintética na ausência de competição. No entanto, a taxa fotossintética foi reduzida com o aumento na intensidade de competição com plantas do biótipo oposto, tanto para o biótipo resistente como para o suscetivel, e também para o biótipo resistente quando em competição com plantas do mesmo biótipo. Atribuiu-se tal comportamento ao aumento no sombreamento mútuo e à competição por luz.
\end{abstract}

Palavras-chave: atividade fotossintética, Lolium multiflorum, incremento de massa.

\begin{abstract}
Characteristics associated with photosynthetic activity of ryegrass biotypes, susceptible and resistant to glyphosate, were evaluated under different competition levels. The experiment was installed in a factorial design, with two ryegrass biotypes, susceptible and resistant to glyphosate, growing in the plot center, surrounded by $0,1,2,3$, and 4 plants of the opposite biotype. Fifty days after emergence, stomatal gas flow rate (U umol $\mathrm{s}^{1}$ ), sub-stomatal $\mathrm{CO}_{2}$ concentration ( $\mathrm{Ci}-\mu \mathrm{mol} \mathrm{mol}^{-1}$ ) and photosynthetic rate $\left(\mathrm{A} \mu \mathrm{mol} \mathrm{m} \mathrm{m}^{-2} \mathrm{~s}^{-1}\right.$ ) were evaluated, with the $\mathrm{CO}_{2}$ used in photosynthesis $\left(\triangle \mathrm{C}-\mu \mathrm{mol} \mathrm{mol} \mathrm{m}^{-1}\right)$ being calculated as the difference between the reference $\mathrm{CO}_{2}$ and the $\mathrm{CO}_{2}$ in the evaluation chamber. Data were collected using an infrared gas analyzer (IRGA), model LCA4 (ADC Company), followed by building a correlation matrix between the variables. The ryegrass biotypes susceptible and resistant to glyphosate did not differ in relation to the photosynthetic activity in absence of competition. However, the photosynthetic rate was reduced in function of increasing competition with plants of the opposite biotype for both the resistant and susceptible biotypes, and for the resistant biotype when in competition with plants of the same biotype. This behavior was attributed to reciprocal shading and light competition.
\end{abstract}

Keywords: photosynthetic activity, Lolium multiflorum, mass increase

1 Aceito para publicação em 26.2.2007 e na forma revisada em 23.7.2008.

2 EngํAgrọ , Doutorando em Fitotecnia da Universidade Federal de Viçosa - UFV, 36570-000 Viçosa-MG, <gconcenco@yahoo.com.br> bolsista CNPq; Engo-Agro ${ }^{\circ}$, D.S. em Fitotecnia, Pós-doutorando do Dep. de Fitotecnia - UFV; ${ }^{4}$ D.S., Professor do Dep. de Fitotecnia - UFV; ${ }^{5}$ D.S., Pesquisador da Embrapa Trigo, Caixa Postal 451, 99001-970 Passo Fundo-RS; ${ }^{6}$ Acadêmica do curso de Agronomia da UFV. 


\section{INTRODUÇÃO}

O azevém é uma espécie daninha anual que infesta lavouras de soja, trigo e pomares no Rio Grande do Sul (Vargas et al., 2005). Seu manejo, há vários anos, normalmente é feito com aplicações repetidas do glyphosate, o que levou ao aparecimento de resistência ao herbicida, fato confirmado por Vargas et al. (2004). Segundo Ferreira et al. (2006), o biótipo resistente de azevém que ocorre na região Sul do País possui menor capacidade competitiva do que o suscetivel ao glyphosate. A capacidade competitiva afeta a quantidade e a qualidade da produção, bem como a eficiência de aproveitamento dos recursos do ambiente, principalmente no que diz respeito às características fisiológicas associadas à fotossíntese e ao acúmulo de massa (VanderZee \& Kennedy, 1983; Melo et al., 2006).

Vários são os fatores que influenciam a fotossintese direta ou indiretamente, como deficiência hídrica, estresse térmico (Loreto \& Bongi, 1989), concentração interna e externa de gases (Kirschbaum \& Pearcey, 1988) e composição e intensidade da luz (Sharkey \& Raschke, 1981), entre outros. Embora a capacidade de condução e trocas gasosas pelos estômatos seja considerada a principal limitação da assimilação de $\mathrm{CO}_{2}$ fotossintético (Hutmacher \& Krieg, 1983), é improvável que as trocas gasosas venham a limitar a taxa de fotossíntese quando em interação com outros fatores.

A taxa fotossintética está diretamente relacionada à radiação fotossinteticamente ativa (composição da luz), aos fatores de disponibilidade hídrica e às trocas gasosas (NavesBarbiero et al., 2000). As plantas possuem necessidades de luz específicas, predominantemente nas faixas do vermelho e azul (Messinger et al., 2006). Se a planta não recebe esses comprimentos de luz de forma satisfatória, necessitará se adaptar para sobreviver (Attridge, 1990). Quando as plantas se encontram sob competição por luz, também se torna importante o balanço na faixa do vermelho e vermelho-distante (Weller et al., 1997), que é afetada pelo sombreamento, influenciando a eficiência fotossintética (Da Matta et al., 2001).

Objetivou-se com este trabalho avaliar as características associadas à atividade fotossintética em biótipos de azevém resistente e suscetivel ao glyphosate, em diferentes níveis de competição.

\section{MATERIAL E MÉTODOS}

O experimento foi instalado em casa de vegetação com irrigação automática, programada para funcionamento por período de 30 min às 8,14 e $18 \mathrm{~h}$, com vistorias diárias para evitar excesso ou falta de água, e a homogeneidade em todos os vasos. As unidades experimentais foram mantidas sob temperatura e iluminação naturais durante a condução do experimento, constando de recipientes plásticos com área de $0,05 \mathrm{~m}^{2}$, perfurados, contendo 6,0 L da mistura pré-elaborada de solo e terra vegetal, corrigido e adubado de acordo com análise de solo, com incorporação um mês antes da implantação do experimento. Os tratamentos constaram de plantas dos biótipos de azevém resistente e suscetivel ao glyphosate. No centro da unidade experimental, foram semeadas três sementes do biótipo de azevém, considerado como o tratamento da unidade experimental ( $R$ para resistente e $S$ para suscetível). Na periferia da unidade experimental foram semeadas dez sementes do biótipo oposto ao do tratamento (central).

Dez dias após a germinação foi efetuado o desbaste, deixando-se apenas uma planta no centro da unidade experimental, e o número de plantas do biótipo oposto, de acordo com o tratamento $(0,1,2,3$ ou 4 plantas). A área de semeadura do biótipo central da unidade experimental foi delimitada por cilindro com $5 \mathrm{~cm}$ de diâmetro e $4 \mathrm{~cm}$ de profundidade, para facilitar a posterior identificação da planta central e de seus perfilhos. O cilindro foi inserido no solo, com a borda superior rente à superfície, permitindo total desenvolvimento das raízes e da parte aérea da planta e plena competição do biótipo central com as demais plantas da periferia, tanto na parte aérea como no sistema de raízes.

O delineamento experimental utilizado foi o de blocos casualizados, com os tratamentos dispostos em esquema fatorial $2 \times 5$, com quatro repetições. As unidades experimentais foram mantidas eqüidistantes, de forma que a área de superficie disponível para o desenvolvimento das plantas correspondesse à área da unidade experimental. 
Aos 50 dias após a emergência, foram realizadas as avaliações, no terço médio da primeira folha completamente expandida do perfilho principal. Foi utilizado um analisador de gases no infravermelho (IRGA), marca ADC, modelo LCA 4 (Analytical Development Co. Ltd, Hoddesdon, UK), em casa de vegetação aberta, permitindo livre circulação do ar. Nessa ocasião, foram determinadas a taxa de fluxo de gases pelos estômatos $\left(\mathrm{U}-\mu \mathrm{mol} \mathrm{s}{ }^{-1}\right)$, a concentração de $\mathrm{CO}_{2}$ subestomática ( $\mathrm{Ci}-\mu \mathrm{mol} \mathrm{mol}^{-1}$ ) e a taxa fotossintética (A $\mu \mathrm{mol} \mathrm{m}^{-2} \mathrm{~s}^{1}$ ), sendo calculado ainda o $\mathrm{CO}_{2}$ consumido $(\Delta \mathrm{C}$ $\mu \mathrm{mol} \mathrm{mol} \mathrm{m}^{-1}$ ) a partir dos valores de $\mathrm{CO}_{2}$ de referência e $\mathrm{CO}_{2}$ na câmara de avaliação. Cada bloco foi avaliado em um dia, entre 8 e 10 horas da manhã, em dia de céu limpo e com iluminação natural, de forma a manter as condições ambientais homogêneas durante a avaliação de cada bloco. Em cada unidade experimental, foram avaliadas a planta central e uma planta periférica escolhida ao acaso.

Os dados foram submetidos à análise de variância pelo teste $\mathrm{F}$ em nível de $5 \%$ de probabilidade, sendo efetuado teste de Duncan a $5 \%$, para avaliar o efeito do aumento na densidade de plantas, e teste da Diferença Mínima Significativa (DMS) a 5\% de probabilidade, para avaliar diferenças entre o biótipo resistente e o suscetível em cada tratamento, além de matriz de correlação, utilizando o programa estatístico Irristat 5.0.

\section{RESULTADOS E DISCUSSÃO}

A taxa de fluxo de gases pelos estômatos (U) não sofreu alteração em função da composição e do arranjo das plantas (Tabela 1). A concentração de $\mathrm{CO}_{2}$ subestomática (Ci) não foi alterada no biótipo suscetivel quando isolado no centro da unidade experimental, nem quando em comunidade (Tabela 2). Por outro lado, o biótipo resistente aumentou a concentração interna de $\mathrm{CO}_{2}$ da folha quando submetido à competição com uma comunidade de plantas do biótipo suscetível, sendo superior aos demais sob competição. No entanto, não se alterou quando este mesmo biótipo foi o formador da comunidade e competia entre si e com uma única planta do biótipo suscetível (Tabela 2). Não foram observadas diferenças entre biótipos em nenhum dos tratamentos. A Ci é considerada variável fisiológica influenciada por fatores ambientais, como disponibilidade hídrica, de luz e energia, entre outros (Ometto et al., 2003). O incremento na $\mathrm{Ci}$ observado no biótipo resistente, quando em competição com plantas mais vigorosas, pode indicar uma tentativa da planta de escapar do estresse gerado pela competição com as plantas do biótipo suscetivel pelos recursos do ambiente (Corniani et al., 2006).

Até recentemente, o mais aceito era que a luz afetava indiretamente a abertura estomática através de seu efeito na assimilação de $\mathrm{CO}_{2}$ (Nishio et al., 1994). No entanto, pesquisas mostraram que a abertura estomática é menos dependente da $\mathrm{Ci}$, respondendo à luz diretamente (Sharkey \& Raschke, 1981). Logo, em condição de competição e sombreamento, o balanço da luz participa no controle da abertura estomática e no balanço de gases entre a parte interna da folha e o meio externo (Loreto \& Bongi, 1989). Em estudos com plantas de girassol submetidas a estresse, a concentração de $\mathrm{CO}_{2}$ na cavidade subestomática (Ci) aumentou, enquanto a taxa de fotossintese (A) foi reduzida (Corniani et al., 2006). Os mesmos resultados foram obtidos neste trabalho. Ao se remover o agente causador do estresse, a planta recuperou a capacidade fotossintética e o Ci foi normalizado (Corniani et al., 2006).

$\mathrm{O} \mathrm{CO}_{2}$ consumido $(\Delta \mathrm{C})$ decresceu tanto no biótipo resistente como no suscetivel quando em plantas isoladas competindo com duas ou mais plantas do biótipo oposto. Quando submetido à competição com plantas do mesmo biótipo e contra apenas uma planta do biótipo oposto, apenas o resistente sofreu redução no consumo de $\mathrm{CO}_{2}$ na maior densidade de plantas (4:(1)). Não foram observadas diferenças entre biótipos (Tabela 3). O mesmo comportamento foi observado para a taxa fotossintética, em que apenas o biótipo suscetível se manteve estável quando em competição com plantas do mesmo biótipo. A exceção se observa quando a competição ocorre contra uma planta do biótipo oposto (Tabela 4), que foi considerado como desvio experimental. A taxa fotossintética diminuiu quando as plantas foram submetidas à competição com plantas do biótipo oposto. Enquanto o biótipo suscetivel foi superior somente na ausência de competição, o biótipo resistente apenas reduziu a taxa fotossintética a partir 
Tabela 1 - Taxa de fluxo de gases pelos estômatos (U) dos biótipos resistente e suscetível ao glyphosate em condição de competição

\begin{tabular}{|l|c|c|c|}
\hline \multirow{2}{*}{$\begin{array}{c}\text { Posição e } \\
\text { número de } \\
\text { plantas }\end{array}$} & \multicolumn{2}{|c|}{ Biótipo de azevém } & \multirow{2}{*}{ Diferença $\mathrm{a}^{\text {// }}$} \\
\cline { 2 - 3 } & Resistente & Suscetível & \\
\hline Centro $^{3 /}$ & \multicolumn{3}{|c|}{$\mathrm{U}-\mu \mathrm{mol} \mathrm{s}^{-1}$} \\
\hline $1(0)$ & $1256 \mathrm{a}^{\frac{2}{}}$ & $1119 \mathrm{a}$ & $+137 \mathrm{~ns}$ \\
\hline $1(1)$ & $1299 \mathrm{a}$ & $1013 \mathrm{a}$ & $+286 \mathrm{~ns}$ \\
\hline $1(2)$ & $1348 \mathrm{a}$ & $1238 \mathrm{a}$ & $+110 \mathrm{~ns}$ \\
\hline $1(3)$ & $1393 \mathrm{a}$ & $1213 \mathrm{a}$ & $+180 \mathrm{~ns}$ \\
\hline $1(4)$ & $1543 \mathrm{a}$ & $1373 \mathrm{a}$ & $+170 \mathrm{~ns}$ \\
\hline Externas & & & \\
\hline $0(1)$ & -- & -- & -- \\
\hline $1(1)$ & $1102 \mathrm{a}$ & $1126 \mathrm{a}$ & $-24 \mathrm{~ns}$ \\
\hline $2(1)$ & $1139 \mathrm{a}$ & $1267 \mathrm{a}$ & $-128 \mathrm{~ns}$ \\
\hline $3(1)$ & $1270 \mathrm{a}$ & $1353 \mathrm{a}$ & $-83 \mathrm{~ns}$ \\
\hline $4(1)$ & $1149 \mathrm{a}$ & $1438 \mathrm{a}$ & $-289 \mathrm{~ns}$ \\
\hline
\end{tabular}

1/ ns - não-significativo pelo teste da DMS

2/ Médias seguidas da mesma letra, na coluna e dentro de cada posição (centro ou externas), não diferem pelo teste de Duncan a $5 \%$ de probabilidade.

${ }^{3} /$ Centro $=$ número de plantas do biótipo indicado no centro da parcela, competindo com o número de plantas (entre parênteses) do biótipo oposto.

4/Externas = número de plantas do biótipo indicado, competindo entre si e com a planta do biótipo oposto (1) no centro da parcela.

do nível de competição 1:(2). As variáveis $\Delta \mathrm{C}$ x A e U x Ci estão diretamente relacionadas e apresentaram correlação em nivel de 1\% (Tabela 5). Conseqüentemente, a concentração de $\mathrm{CO}_{2}$ interna da folha está associada à capacidade de trocas gasosas com o meio externo.

A fotossintese e, conseqüentemente, a respiração dependem de constante fluxo de $\mathrm{CO}_{2} \mathrm{e}$ $\mathrm{O}_{2}$ entrando e saindo da célula; esse fluxo livre é função da concentração de $\mathrm{CO}_{2} \mathrm{e} \mathrm{O}_{2}$ nos espaços intercelulares dependentes da abertura estomática, controladora majoritária do fluxo de gases (Taylor Jr. \& Gunderson, 1986; Messinger et al., 2006). Esta, por sua vez, é em grande parte controlada pela turgescência tanto das células-guarda (que controlam a abertura dos estômatos) como das células epidérmicas dos estômatos (Humble \& Hsiao, 1970). Um potencial hídrico baixo, que induz o fechamento do estômato e reduz a condutância foliar, inibe a fotossintese e também a
Tabela 2 - Concentração de $\mathrm{CO}_{2}$ subestomática (Ci) dos biótipos resistente e suscetível ao glyphosate em condição de competição

\begin{tabular}{|l|c|c|c|}
\hline \multirow{2}{*}{$\begin{array}{c}\text { Posição e } \\
\text { número } \\
\text { de plantas }\end{array}$} & \multicolumn{2}{|c|}{ Biótipo de azevém } & \multirow{2}{*}{ Riferença $^{1 /}$} \\
\cline { 2 - 3 } & Resistente & Suscetível & \\
\hline Centro $^{3 /}$ & \multicolumn{3}{|c|}{$\mathrm{Ci}-\mu \mathrm{mol} \mathrm{mol}^{-1}$} \\
\hline $1(0)$ & $951 \mathrm{~b}^{2 /}$ & $1072 \mathrm{a}$ & $-121 \mathrm{~ns}$ \\
\hline $1(1)$ & $1025 \mathrm{~b}$ & $969 \mathrm{a}$ & $+56 \mathrm{~ns}$ \\
\hline $1(2)$ & $1339 \mathrm{ab}$ & $1276 \mathrm{a}$ & $+63 \mathrm{~ns}$ \\
\hline $1(3)$ & $1259 \mathrm{ab}$ & $1270 \mathrm{a}$ & $-11 \mathrm{~ns}$ \\
\hline $1(4)$ & $1529 \mathrm{a}$ & $1171 \mathrm{a}$ & $+358 \mathrm{~ns}$ \\
\hline Externas & & & \\
\hline $0(1)$ & -- & -- & -- \\
\hline $1(1)$ & $1012 \mathrm{a}$ & $824 \mathrm{a}$ & $+188 \mathrm{~ns}$ \\
\hline $2(1)$ & $1186 \mathrm{a}$ & $1162 \mathrm{a}$ & $+24 \mathrm{~ns}$ \\
\hline $3(1)$ & $1189 \mathrm{a}$ & $1210 \mathrm{a}$ & $-21 \mathrm{~ns}$ \\
\hline $4(1)$ & $1232 \mathrm{a}$ & $1280 \mathrm{a}$ & $-48 \mathrm{~ns}$ \\
\hline
\end{tabular}

${ }^{1 /} \mathrm{ns}=$ não-significativo pelo teste da DMS

2/ Médias seguidas da mesma letra, na coluna e dentro de cada posição (centro ou externas), não diferem pelo teste de Duncan a $5 \%$ de probabilidade.

${ }^{3} /$ Centro $=$ número de plantas do biótipo indicado no centro da parcela, competindo com o número de plantas (entre parênteses) do biótipo oposto.

4/Externas = número de plantas do biótipo indicado, competindo entre si e com a planta do biótipo oposto (1) no centro da parcela.

respiração (Attridge, 1990). A taxa fotossintética (Tabela 4) está diretamente relacionada com o consumo de $\mathrm{CO}_{2}$ do meio (Tabela 3) e se mostrou independente da concentração de $\mathrm{CO}_{2}$ subestomática $(\mathrm{A} \times \mathrm{Ci}$ Tabela 5) e da taxa de fluxo de gases pelos estômatos (A x U - Tabela 5).

O balanço e composição da radiação incidente sobre a planta quando em competição, ou condição de sombreamento, aliado ao nível de carboidratos nas folhas, podem aumentar a taxa respiratória diretamente ou através de vias alternativas associadas à cadeia respiratória (Pystina \& Danilov, 2001), o que poderia tornar o saldo da fotossintese ainda menor e reduzir a capacidade de acúmulo de massa da planta. Quando as plantas estão em condições de sombreamento, a reação natural é favorecer o alongamento da planta em vez do acúmulo de massa (Weller et al., 1997). Essa resposta está diretamente associada ao balanço de radiação na faixa do vermelho e vermelho- 
Tabela 3 - $\mathrm{CO}_{2}$ consumido $(\Delta \mathrm{C})$ dos biótipos resistente e suscetível ao glyphosate em condição de competição

\begin{tabular}{|l|c|c|c|}
\hline \multirow{2}{*}{$\begin{array}{c}\text { Posição e } \\
\text { número } \\
\text { de plantas }\end{array}$} & \multicolumn{2}{|c|}{ Biótipo de azevém } & \multirow{2}{*}{ Diferença $^{1 /}$} \\
\cline { 2 - 3 } & Resistente & Suscetível & \\
\hline Centro $^{3 /}$ & \multicolumn{3}{|c|}{$\Delta \mathrm{C}-\mu \mathrm{mol} \mathrm{mol}^{-1}$} \\
\hline $1(0)$ & $36,65 \mathrm{a}^{2 /}$ & $32,96 \mathrm{a}$ & $+3,69 \mathrm{~ns}$ \\
\hline $1(1)$ & $32,96 \mathrm{ab}$ & $32,03 \mathrm{a}$ & $+0,93 \mathrm{~ns}$ \\
\hline $1(2)$ & $22,01 \mathrm{~b}$ & $24,26 \mathrm{~b}$ & $-2,25 \mathrm{~ns}$ \\
\hline $1(3)$ & $21,76 \mathrm{~b}$ & $18,89 \mathrm{c}$ & $+2,87 \mathrm{~ns}$ \\
\hline $1(4)$ & $21,66 \mathrm{~b}$ & $16,44 \mathrm{c}$ & $+5,22 \mathrm{~ns}$ \\
\hline Externas ${ }^{4 /}$ & & & \\
\hline $0(1)$ & -- & -- & -- \\
\hline $1(1)$ & $26,20 \mathrm{a}$ & $18,77 \mathrm{a}$ & $+7,43 \mathrm{~ns}$ \\
\hline $2(1)$ & $27,70 \mathrm{a}$ & $25,33 \mathrm{a}$ & $+2,37 \mathrm{~ns}$ \\
\hline $3(1)$ & $26,99 \mathrm{a}$ & $21,46 \mathrm{a}$ & $+5,53 \mathrm{~ns}$ \\
\hline $4(1)$ & $17,67 \mathrm{~b}$ & $20,48 \mathrm{a}$ & $-2,81 \mathrm{~ns}$ \\
\hline
\end{tabular}

${ }^{1 /} \mathrm{ns}=$ não-significativo pelo teste da DMS.

2/ Médias seguidas da mesma letra, na coluna e dentro de cada posição (centro ou externas), não diferem pelo teste de Duncan a $5 \%$ de probabilidade.

${ }^{3 /}$ Centro = número de plantas do biótipo indicado no centro da parcela, competindo com o número de plantas (entre parênteses) do biótipo oposto.

4/ Externas = número de plantas do biótipo indicado, competindo entre si e com a planta do biótipo oposto (1) no centro da parcela.

Tabela 5 - Análise de correlação entre as características fotossintéticas avaliadas em função da competição entre biótipos resistentes e suscetíveis ao glyphosate

\begin{tabular}{|c|c|c|c|}
\hline Variáveis & Interação & Variáveis & Interação \\
\hline $\mathrm{A} \times \mathrm{U}$ & $0,628 \mathrm{~ns}$ & $\mathrm{U} \times \mathrm{Ci}$ & $0,955 * *$ \\
\hline $\mathrm{A} \times \mathrm{Ci}$ & $0,525 \mathrm{~ns}$ & $\mathrm{U} \times \Delta \mathrm{C}$ & $-0,621 \mathrm{~ns}$ \\
\hline $\mathrm{A} \times \Delta \mathrm{C}$ & $-0,979 * *$ & $\mathrm{Ci} \times \Delta \mathrm{C}$ & $-0,519 \mathrm{~ns}$ \\
\hline
\end{tabular}

$\mathrm{ns}=$ correlação não-significativa; $* *$ correlação significativa a $1 \%$ de probabilidade.

$\mathrm{U}=$ taxa de fluxo de gases pelos estômatos; $\mathrm{Ci}=$ concentração de $\mathrm{CO}_{2}$ subestomática; $\Delta \mathrm{C}=\mathrm{CO}_{2}$ consumido; $\mathrm{A}=$ taxa fotossintética

distante percebidos pelos fitocromos que se interconvertem entre as duas formas, fazendo com que a planta se alongue para escapar do sombreamento e, após, assuma crescimento mais generalizado e homogêneo, com acúmulo de massa proporcional ao seu tamanho. Várias espécies de plantas daninhas e culturas comerciais alteram a taxa fotossintética em diferentes níveis sob mesmas condições ambientais (Procópio et al., 2004).
Tabela 4 - Taxa fotossintética (A) dos biótipos resistente e suscetível ao glyphosate em condição de competição

\begin{tabular}{|l|c|c|c|}
\hline \multirow{2}{*}{$\begin{array}{c}\text { Posição e } \\
\text { número } \\
\text { de plantas }\end{array}$} & \multicolumn{2}{|c|}{ Biótipo de azevém } & \multirow{2}{*}{ Diferença $^{1 /}$} \\
\cline { 2 - 3 } & Resistente & Suscetível & \\
\hline Centro $^{3 /}$ & \multicolumn{3}{|c|}{$\mathrm{A}-\mu \mathrm{mol} \mathrm{m}^{-2} \mathrm{~s}^{-1}$} \\
\hline $1(0)$ & $15,10 \mathrm{a}^{2^{\prime}}$ & $13,56 \mathrm{a}$ & $+1,54 \mathrm{~ns}$ \\
\hline $1(1)$ & $15,61 \mathrm{a}$ & $9,47 \mathrm{~b}$ & $+6,14 *$ \\
\hline $1(2)$ & $9,11 \mathrm{~b}$ & $7,51 \mathrm{~b}$ & $+1,6 \mathrm{~ns}$ \\
\hline $1(3)$ & $9,45 \mathrm{~b}$ & $8,90 \mathrm{~b}$ & $+0,55 \mathrm{~ns}$ \\
\hline $1(4)$ & $9,24 \mathrm{~b}$ & $8,48 \mathrm{~b}$ & $+0,76 \mathrm{~ns}$ \\
\hline Externas & & & \\
\hline $0(1)$ & -- & -- & -- \\
\hline $1(1)$ & $12,80 \mathrm{a}$ & $9,22 \mathrm{a}$ & $+3,58 \mathrm{~ns}$ \\
\hline $2(1)$ & $13,02 \mathrm{a}$ & $10,10 \mathrm{a}$ & $+2,92 \mathrm{~ns}$ \\
\hline $3(1)$ & $11,32 \mathrm{ab}$ & $8,33 \mathrm{a}$ & $+2,99 \mathrm{~ns}$ \\
\hline $4(1)$ & $7,08 \mathrm{~b}$ & $9,85 \mathrm{a}$ & $-2,77 \mathrm{~ns}$ \\
\hline
\end{tabular}

${ }_{1 /} \mathrm{ns}=$ não-significativo; $*$ significativo a $5 \%$ pelo teste da DMS.

2/ Médias seguidas da mesma letra, na coluna e dentro de cada posição (centro ou externas), não diferem pelo teste de Duncan a $5 \%$ de probabilidade.

${ }^{3} /$ Centro $=$ número de plantas do biótipo indicado no centro da parcela, competindo com o número de plantas (entre parênteses) do biótipo oposto.

${ }^{4}$ Externas = número de plantas do biótipo indicado, competindo entre si e com a planta do biótipo oposto (1) no centro da parcela.

Os biótipos de azevém resistente e suscetivel ao glyphosate não diferiram quanto à atividade fotossintética na ausência de competição. No entanto, a taxa fotossintética foi reduzida com o aumento na intensidade de competição com plantas do biótipo oposto, tanto para o biótipo resistente como para o suscetível, e também para o biótipo resistente quando em competição com plantas do mesmo biótipo. Atribuiu-se tal comportamento ao aumento no sombreamento mútuo e competição por luz.

\section{LITERATURA CITADA}

ATTRIDGE, T. H. The natural light environment. In: ATTRIDGE, T. H. (Ed.). Light and plant responses London: Edward Arnold, 1990. p. 1-5.

CORNIANI, N. et al. Determinação das trocas gasosas e de potencial hídrico através do uso de sistemas portáteis na avaliação do estresse. In: SIMPÓSIO INTERNACIONAL DE INICIAÇÃO CIENTÍFICA DA UNIVERSIDADE DE SÃO PAULO, 14., 2006, Piracicaba. Anais... São Paulo: Universidade de São Paulo, 2006. CD-ROM. 
DA MATTA, F. M. et al. Actual and potential photosynthetic rates of tropical crop species. R. Bras. Fisiol. Veg., v. 13, n. 1, p. 24-32, 2001.

FERREIRA, E. A. et al. Translocação do glyphosate em biótipos de azevém (Lolium multiflorum). Planta Daninha, v. 24, n. 2, p. 365-370, 2006.

KIRSCHBAUM, M. U. F.; PEARCY, R. W. Gas exchange analysis of the relative importance of stomatal and biochemical factors in phosynthetic induction in Alocasia macrorrhiza. Plant Physiol., v. 86, n. 3, p. 782-785, 1988

HUMBLE, G. D.; HSIAO, T. C. Light-dependent influx and efflux of potassium of guard cells during stomatal opening and closing. Plant Physiol., v. 46, n. 3, p. 483-487, 1970.

HUTMACHER, R. B.; KRIEG, D. R. Photosynthetic rate control in cotton. Plant Physiol., v. 73, n. 3, p. 658-661, 1983.

LORETO, F.; BONGI, G. Combined low temperature-high light effects on gas exchange properties of jojoba leaves.

Plant Physiol., v. 91, n. 4, p. 1580-1585, 1989.

MELO, P. T. B. S. et al. Comportamento de populações de arroz irrigado em função das proporções de plantas originadas de sementes de alta e baixa qualidade fisiológica.

R. Bras. Agroc., v. 12, n. 1, p. 37-43, 2006

MESSINGER, S. M. et al. Evidence for involvement of photosynthetic processes in the stomatal response to $\mathrm{CO}_{2}$. Plant Physiol., v. 140, n. 2, p. 771-778, 2006.

NAVES-BARBIERO, C. C. et al. Fluxo de seiva e condutância estomática de duas espécies lenhosas sempreverdes no campo sujo e cerradão. R. Bras. Fisiol. Veg., v. 12, n. 1, p. 119-134, 2000.

NISHIO, J. N.; SUN, J.; VOGELMANN, T. C.

Photoinhibition and the light environment within leaves. In: BAKER, N. R.; BOWYER, J. R. (Eds.). Photoinhibition of photosynthesis. Oxford: BIOS Scientific Publishers, 1994. p. $1-24$
OMETTO, J. P. H. B. et al. Variação temporal do isótopo estável do carbono em material arbóreo em florestas da região Amazônica. In: CONGRESSO BRASILEIRO DE ECOLOGIA, 4., 2003, Fortaleza. Anais... Rio Claro: Sociedade de Ecologia do Brasil, 2003. CD-ROM.

PROCÓPIO, S. O. et al. Características físiológicas das culturas de soja e feijão e de três espécies de plantas daninhas. Planta Daninha, v. 22, n. 2, p. 211-216, 2004

PYSTINA, N. V.; DANILOV, R. A. Influence of light regimes on respiration, activity of alternative respiratory pathway and carbohydrates content in mature leaves of Ajuga reptans L. R. Bras. Fisiol. Veg., v. 13, n. 3, p. 285292, 2001.

SHARKEY, T. D.; RASCHKE, K. Effect of light quality on stomatal opening in leaves of Xanthium strumarium $\mathrm{L}$. Plant Physiol., v. 68, n. 5, p. 1170-1174, 1981.

TAYLOR Jr., G. E.; GUNDERSON, C. A. The response of foliar gas exchange to exogenously applied ethylene. Plant Physiol., v. 82, n. 3, p. 653-657, 1986

VANDERZEE, D.; KENNEDY, R. A. Development of photosynthetic activity following anaerobic germination in rice-mimic grass (Echinochloa crus-galli var oryzicola). Plant Physiol., v. 73, n. 2, p. 332-339, 1983.

VARGAS, L. et al. Identificação de biótipos de azevém (Lolium multiflorum) resistentes ao herbicida glyphosate em pomares de maçã. Planta Daninha, v. 22, n. 2, p. 617-622, 2004.

VARGAS, L. et al. Alteração das características biológicas dos biótipos de azevém (Lolium multiflorum) ocasionada pela resistência ao herbicida glyphosate. Planta Daninha, v. 23, n. 1, p. $153-160,2005$

WELLER, J. L.; MURFET, I. C.; REID, J. B. Pea mutants with reduced sensitivity to far-red light define an important role for phytochrome A in day-length detection. Plant

Physiol., v. 114, n. 4. p. 1225-1236, 1997. 